Ein Kommentar zu Friedrich Nietzsche, "Die Geburt der Tragödie aus dem Geiste der Musik« (Kap. 1-12) 
Barbara von Reibnitz

\section{Ein Kommentar zu Friedrich Nietzsche, \\ »Die Geburt der Tragödie aus dem Geiste der Musik«}

(Kap. 1-12) 
Die Deutsche Bibliothek - CIP-Einheitsaufnahme Relbnitz, Barbara von:

Ein Kommentar zu Friedrich Nietzsche, $"$ Die Geburt der Tragödie aus dem Geiste der Musik«, Kap. 1-12 / Barbara von

Reibnitz. - Stuttgart : Metzler, 1992 ISBN 978-3-476-00832-9

ISBN 978-3-476-03407-6 (eBook)

DOI 10.1007/978-3-476-03407-6

Zugl.: Tübingen, Eberhard-Karls-Universität, Diss. 1989

Dieses Werk einschlieBlich aller seiner Teile ist urheberrechtlich geschützt. Jede Verwertung außerhalb der engen Grenzen des Urheberrechtsgesetzes ist ohne Zustimmung des Verlages unzulässig und strafbar. Das gilt insbesondere für Vervielfaltigungen, Übersetzungen, Mikroverfilmungen und die Einspeicherung und Verarbeitung in elektronischen Systemen.

(C) 1992 Springer-Verlag GmbH Deutschland

Ursprünglich erschienen bei J.B. Metzlersche Verlagsbuchhandlung und Carl Ernst Poeschel Verlag GmbH in Stuttgart 1992 
meinem Vater 


\section{INHALT}

\section{Danksagung}

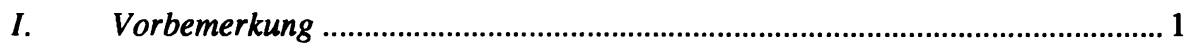

1. Gegenstand der Kommentierung ....................................................................... 1

2. Zielsetzung und Umfang der Kommentierung .................................................4

3. Bemerkungen zum Forschungsstand .....................................................................

4. Anlage und Form des Kommentars ...................................................................

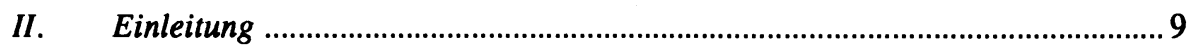

1. Die philologischen Voraussetzungen der GT ..............................................

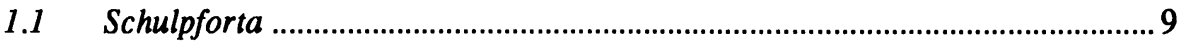

1.1.1 Allgemeine Interessen ................................................................................... 10

1.1.2 Entwürfe und Arbeiten zu antiken Themen .......................................................11

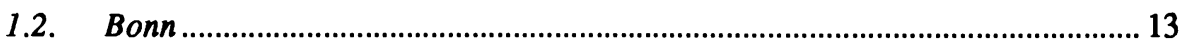

1.2.1 Theognis-Studien ............................................................................................. 14

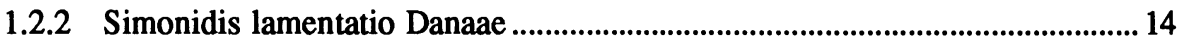

1.2.3 Longini de sublimitate libellus ...................................................................... 14

1.2.4 Sonstige Interessen und Arbeiten der Bonner Zeit ............................................. 15

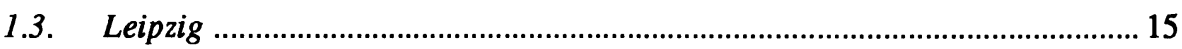

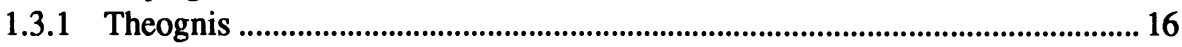

1.3.2 Notizen, Pläne, Entwürfe zum Thema >Tragödie< ……………………………..... 17

1.3.3 Die Arbeiten zu Diogenes Laertius .................................................................... 19

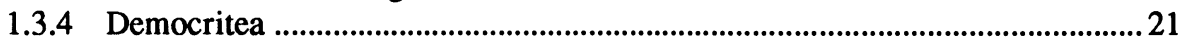

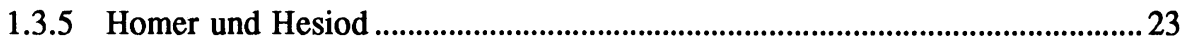

1.3.6 Summa: »Die Geschichte der litterarischen Studien im Alterthum und in der Neuzeit « ...................................................................... 23

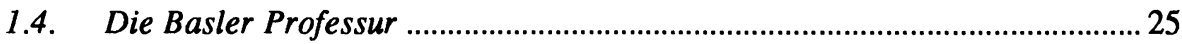

1.4.1 Vorlesung SS 1869 „Die griechischen Lyriker« ..................................................2 27

1.4.2 Vorlesung SS 1870 „Sophokles' Oedipus Rex « ..............................................28

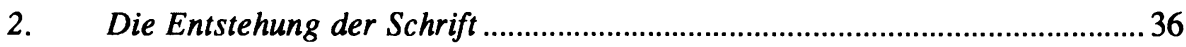

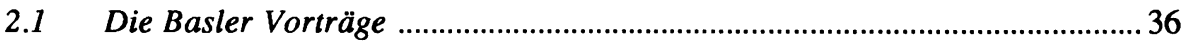


2.1.1 „Das griechische Musikdrama« ...........................................................................37

2.1.2 »Sokrates und die Tragödie« ............................................................................ 38

2.2 Die Basler Abhandlungen .........................................................................40

2.2.1 $\gg$ Die dionysische Weltanschauung « .....................................................................42

2.2.2 „Ursprung und Ziel der Tragödie« ...............................................................43

2.2.3 "Socrates und die griechische Tragödie« ............................................................46

$2.3 \quad$ Exkurs zum Manuskriptbestand ..............................................................49

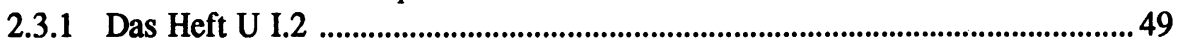

2.3.2 Zur Textgenese von GT 1-15 ........................................................................5 52

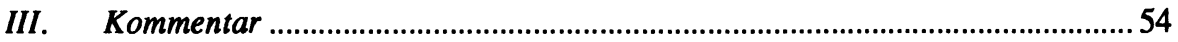

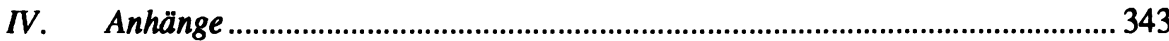

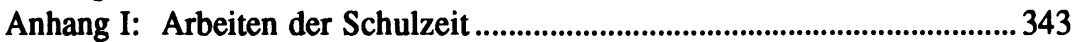

Anhang II: Materialien und Arbeiten der Studienzeit ...................................344

Anhang III: Liste der Lehrveranstaltungen bis SS 1872 ................................348

Anhang IV: Nietzsches Arbeitsmittel ............................................................351

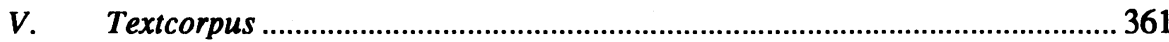

I Paralleltexte Nietzsches zu GT

I.1 Vorlesung »Die griechischen Lyriker« (Auszug) ..............................................361

I.2 »Die drei griechischen Tragiker« (vollständig). ................................................365

I.3 Vorlesung »Sophokles, Oedipus Rex«, § 1 »Die antike und die neuere Tragödie in Ansehung ihres Ursprungs« (Auszug). .......................366

I.4 Vorlesung »Geschichte der griechischen Literatur«

1. Teil, $\$ 8$ »Die Tragödie« (Auszug).

II Sekundärliteratur

II.1 K.O. Müller, Geschichte der griechischen Literatur, Kap. 21 »Ursprünge der dramatischen Poesie« (Auszug). .............................. 371

II.2 P. Yorck v. Wartenburg, Die Katharsis des Aristoteles und der Oedipus Coloneus des Sophokles, S. 20-24 (Auszug).

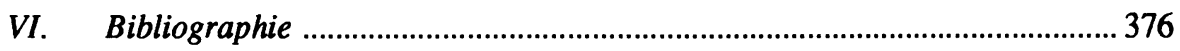

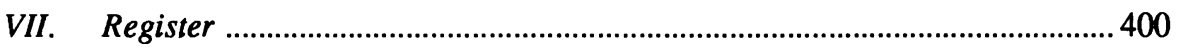


Diese Arbeit hat im Herbst 1989 dem Fachbereich Kulturwissenschaften an der Universităt Tübingen als Dissertation vorgelegen und wird hier ohne wesentliche Änderungen veröffentlicht. Seither erschienene Literatur konnte nur selektiv berücksichtigt werden. Nachträgliche Ergänzungen betreffen lediglich die Bemerkungen zur Textgenese der Tragödienschrift. Sie ergaben sich aus einer Einsichtnahme in die Manuskripte im Archiv der Nationalen Forschungs- und Gedenkstătten Weimar.

Die Dissertation wurde angeregt durch Prof. Hubert Cancik, dem ich für seine kontinuierliche und kritische Förderung in Methodik und Fragestellung vor allem zu danken habe.

Mein Dank gilt im weiteren Herrn Prof. B. Gladigow für seine Begutachtung und Kritik der gesamten Arbeit, den Herren Professoren J. Bollack, A. Henrichs, B. Kytzler, G.W. Most, A. Laks, B. Seidensticker sowie Frau Dr. R. Schlesier für die kritische Lektüre und Diskussion einzelner Kapitel.

Ohne die Unterstützung und Kritik meiner Freunde wăre diese Arbeit nicht zu Ende geführt worden, ich möchte unter ihnen besonders Peter Dð̈tling sowie Christian Brockmann, Richard Faber, Irene Ghisu, Peter Habermehl, Niklaus Peter, Susanne Rothe, Gerson Schade und Martin Vöhler danken. Für freundschaftliche Unterstützung und technischen Beistand bei der Erstellung des Manuskripts danke ich außerdem Herrn Dr. Christian Wildberg.

In Basel haben die Herausgeber des Nachberichts zur Abteilung III der Kritischen Nietzsche - Ausgabe, Wolfram Groddeck und Michael Kohlenbach, mir freundlich Auskunft über und Einsicht in die ihnen zur Verfügung stehenden Manuskripte gewährt - auch ihnen gilt mein herzlicher Dank.

Basel, im November 1991. 